\title{
UMA ANÁLISE SOBRE HABILIDADES NARRATIVAS NAS PROPOSIÇÕES DE UM CURRÍCULO BILÍNGUE PARA SURDOS
}

\author{
AN ANALYSIS ON NARRATIVE SKILLS IN THE PROPOSITIONS \\ OF A BILINGUAL CURRICULUM FOR THE DEAF
}

Felipe Venâncio Barbosa

Universidade de São Paulo felipebarbosa@usp.br

Lourdes Fátima Basílio

Universidade de São Paulo lourdesbf23@gmail.com

\author{
Márcia Cruz \\ Universidade Federal de São Carlos \\ mrccruz2@gmail.com
}

\begin{abstract}
Resumo
A Secretaria Municipal de Educação da Cidade de São Paulo publicou dois documentos específicos para a Educação de Surdos em 2019. Trata-se do Currículo Bilíngue, parte integrante do Currículo da Cidade. Tendo as habilidades narrativas como centro da aquisição e desenvolvimento de linguagem e dos impactos deste desenvolvimento no aprendizado de segunda língua, este trabalho pretende apresentar uma análise sobre as proposições destes documentos com relação aos objetivos de desenvolvimento e aprendizagem baseados em habilidades comunicativas e linguísticas que mobilizam o domínio da compreensão e produção de narrativas. Os documentos apresentam o desenvolvimento bilíngue do estudante surdo como foco, com a aquisição plena da Língua Brasileira de Sinais (Libras) e domínio metalinguístico de sua estrutura e com o desenvolvimento da leitura e escrita, como segunda língua, autônoma. Também aborda aspectos como identidade, cultura surda, cultura ouvinte, interculturalidade, funções da linguagem e literaturas, mobilizando habilidades narrativas em mais de $30 \%$ de seus objetivos de aprendizagem e desenvolvimento. Trata-se de um documento que propõe uma relação intrínseca entre uso e conhecimento das línguas, colocando a Libras como fundamento para a construção de outros conhecimentos e para o desenvolvimento integral do estudante.
\end{abstract}

Palavras-chave: narrativas, bilinguismo, currículo, língua de sinais, segunda língua

\section{Abstract:}

The Education Secretariat of the City of São Paulo published two documents for the Education of the Deaf in 2019; that is, the Bilingual Curriculum, which is an integral part of the City Curriculum. Considering the narrative skills as the centre of language acquisition and development and their strong impact on second language learning, this paper presents an analysis on the propositions of these documents, in relation to the development and learning objectives, which, in turn, are based on the communicative and linguistic skills that mobilize the field of narrative comprehension and production. The documents focus on the bilingual development of the deaf student, through the full acquisition of the Brasilian Sign Language (Libras) and the metalinguistic mastery of its structure, and on the development of autonomous reading and writing skills as a second language. It also addresses aspects such as identity, deaf 
culture, hearing culture, interculturality, language functions and literature, mobilizing narrative skills in more than $30 \%$ of its learning and development objectives. It is a document that proposes an intrinsic relationship between use and knowledge of languages, placing Libras as a foundation for the construction of other knowledge and for the integral development of the student.

Key-words: narratives, bilingualism, educational curriculum, sign language, second language.

\section{Introdução}

O termo "aquisição de linguagem" é usado para fazer referência a diferentes processos, entre eles, a aquisição natural de primeira língua, a aquisição natural de uma segunda ou múltiplas línguas, aquisição de língua em ambiente formal (aprendizagem) e o reaprendizado de primeira língua em ambiente terapêutico. Esses processos constituem a construção do conhecimento linguístico em si, observando as condições, as formas como se dão, as etapas e o período que ocorrem (BUSSMANN, 1999)

A aquisição e o aprendizado de línguas na Educação de Surdos tem sido tema controverso de debate desde o século XIX. Documentos relativos a congressos sobre educação de Surdos datam de 1879, segundo Kynsey (2011), Rodrigues (2018), Rodrigues e Vieira-Machado (2019), e propunham discussões a respeito das línguas orais e de sinais para estudantes surdos. Pode-se dizer que também discutia-se o que seriam os primórdios das proposições curriculares no que diz respeito à aquisição e ensino de línguas para surdos.

A aquisição de língua e o desenvolvimento de linguagem são influenciados pelos estímulos que a criança recebe do meio (BISHOP, 2002). Assim como para o desenvolvimento cognitivo adequado, a linguagem necessita de subsídios vindo do input gerado pelos usuários de uma língua, membros da comunidade em que a criança está imersa, além de outros componentes como os psicológicos e os sociais (BISHOP, 2002), que também participam do processo de aquisição de língua e desenvolvimento de linguagem. A acessibilidade à língua é, então, um princípio para que a própria língua seja adquirida e para que haja desenvolvimento da linguagem e da cognição adequados.

Uma língua oral exige, para sua aquisição integral, que as habilidades auditivas estejam preservadas (BORGES; SALOMÃO, 2003). São muitos os estudos encontrados na literatura científica que relacionam as perdas auditivas com os insucessos na aquisição de língua e desenvolvimento de linguagem (BALBANI; MANTOVANI, 2003). No caso da criança surda com perda auditiva severa e/ou profunda, o acesso a esta modalidade de língua fica sobremodo comprometido e isso torna a aquisição da língua oral uma tarefa árdua, não ocorrendo de forma natural (LEVY; BARBOSA, 2004). A melhor e mais coerente forma de estimulação de linguagem para uma criança surda é, portanto, aquela que se baseia na utilização das línguas de sinais como primeira língua - o que não descarta o aprendizado da língua oral (PIKERSGILL, 1998).

As línguas de sinais são línguas naturais de modalidade viso-espacial utilizadas pelas comunidades surdas (BRITO, 1995; QUADROS, 1997; QUADROS; KARNOPP, 2004). São línguas que não dependem da audição para serem adquiridas, são completas e propiciam integralmente a estruturação das habilidades cognitivas. Por não dependerem da audição, são línguas naturalmente adquiridas pelas pessoas surdas e através delas, as informações são facilmente compreendidas e a expressão das idéias da pessoa surda são veiculadas sem impedimentos.

Por isso, a proposição do bilinguismo para surdos - aquisição da Língua Brasileira de Sinais (Libras) como primeira língua e ensino da Língua Portuguesa como segunda língua - passa a ser observada como a alternativa que propicia condições para o desenvolvimento adequado do indivíduo das crianças surdas (LICHTIG et al., 2014) e passa-se a discutir o que ensinar (nas duas línguas) e como ensinar. 
Nos dois últimos anos, a Secretaria de Educação do Município de São Paulo (SME-SP) publica dois documentos para a Educação de Surdos, constituintes do Currículo da Cidade: o Currículo de Língua Brasileira de Sinais (SME-SP, 2019a) e o Currículo de Língua Portuguesa para Surdos (SME-SP, 2019b). As publicações sistematizam os objetivos de aprendizagem e desenvolvimento para o ensino de Libras e Língua Portuguesa para Surdos, sendo o primeiro currículo bilíngue proposto no Brasil em consonância com a Base Nacional Comum Curricular.

A proposição de um currículo é uma forma de sistematizar o conhecimento e as aprendizagens construídas para a formação (PACHECO, 2005), que apresentam objetivos concomitantes e interconectados, levando em conta o ambiente escolar e as relações de interação e ação entre os participantes (DOLL, 1997). Evitando a prescrição de conteúdos específicos e com foco em habilidades cognitivas e linguísticas para a aquisição de qualquer conhecimento desejado, as proposições de um currículo devem possuir intersecções que permitam que sua consistência.

A decisão sobre o que constituirá o currículo para o ensino de línguas para surdos certamente leva em consideração as diversas habilidades cognitivas e de linguagem mobilizadas no processo de aquisição de primeira língua e aprendizagem de segunda língua. As habilidades narrativas são imprescindíveis nesses processos de aquisição e aprendizagem de línguas e devem fazer parte do processo de forma natural.

A narrativa é uma produção linguística que pode ser expressa por meio da escrita, da fala ou da sinalização. Segundo Rathmann et al. (2007), sua produção envolve a mobilização de três domínios cognitivos: os dispositivos linguísticos usados em unidades discursivas maiores, incluindo episódios e configurações (PETERSON; MCCABE, 1990); as habilidades pragmáticas, incluindo a consciência de um parceiro de conversação ou necessidades de informação específicas ao destinatário (HUDSON; SHAPIRO, 1991) e as habilidades cognitivas gerais, como a memória de trabalho e o processamento de informações para o sequenciamento de grandes quantidades de informação (EISENBERG, 1985).

Morgan (2002) e Morgan e Woll (2003) investigaram narrativas em Língua de Sinais Britânica (BSL) e propuseram alguns marcos gerais para suas análises. Para os autores, as crianças surdas bem-sucedidas em seu desenvolvimento de habilidades narrativas usam este recurso linguístico e cognitivo como degrau para a aquisição de outra língua. Autores como Quadros (1997), Lacerda e Mantelatto (2000) e Lodi (2000) caratrerizam o domínio da Libras como uma condição para o aprendizado adequado da Língua Portuguesa, ornando-se essencial não apenas para a obtenção de conhecimento de mundo, mas para a aquisição de outras competências.

O domínio das habilidades narrativas envolve, além das habilidades cognitivas citadas anteriormente, a competência no uso da gramática da língua e da organização da estrutura discursiva. Demanda um ambiente essencialmente dialógico e hermenêutico (LABOV, 1997), permitindo a compreensão da linguagem e da vida social e catalisa o processo de aprendizado de crianças e o ensino de línguas (SOUZA; BERNADINO, 2011).

Diante da importância das habilidades narrativas para os processos de aprendizagem, este trabalho se propõe a apresentar uma análise sobre as proposições do Currículo Bilíngue da Cidade com relação aos objetivos de desenvolvimento e aprendizagem baseados em habilidades comunicativas e linguísticas que mobilizam o domínio da compreensão e produção de narrativas. 


\section{0 currículo bilíngue para surdos da cidade de São Paulo}

A SME-SP publicou no ano de 2019 uma série de documentos que chamou de Currículo da Cidade. o objetivo da iniciativa foi de propor um alinhamento com as orientações curriculares propostas na Base Nacional Comum Curricular (BNCC), concretizando o projeto nacional com a implementação de um currículo local.

Em consulta realizada em abril de 2020 ao site da SME-SP foi possível observar a disponibilização dos materiais na página do Currículo da Cidade. Os materiais publicados contemplam a Educação Infantil, com uma publicação com este nome; o Ensino Fundamental e a Educação de Jovens e Adultos, com nove publicações cada, que contemplam os componentes Tecnologias de Aprendizagem, Matemática, Língua Portuguesa, Língua Inglesa, História, Geografia, Educação Física, Ciências Naturais e Arte específicos para as duas realidades; treze cadernos de orientações didáticas para os componentes curriculares, incluindo edições específicas para Coordenação Pedagógica e para Povos Indígenas e, objeto de nossa análise neste trabalho, a Educação Especial, com duas publicações distintas mas componentes de um mesmo projeto de Currículo Bilíngue para Surdos: Língua Brasileira de Sinais e Língua Portuguesa para Surdos.

O processo de construção do Currículo Bilíngue para Surdos é descrito, em parte, nas páginas de apresentação dos documentos (SME-SP, 2019a; 2019b) e por Horta et al. (2020). Com a participação de profissionais surdos e ouvintes da rede de ensino divididos em grupos de trabalho, a SME-SP propõe documentos que se estruturam em um capítulo introdutório (Parte 1), presente nos demais documentos, exceto o Currículo da Cidade - Educação Infantil e nos cadernos de Orientações Didáticas, em um capítulo específico sobre o Currículo Bilíngue (Parte 2) e em uma capítulo que apresenta os Objetos de Aprendizagem e Desenvolvimento para os dois componentes curriculares - Língua Brasileira de Sinais e Língua Portuguesa para Surdos (Parte 3).

A Parte 2 foi consturída com uma introdução sobre a Educação de Surdos, contemplando os tópicos relevantes para a compreensão do tema; uma seção com a exposição dos conceitos fundamentadores do documento, destacando o conhecimento metalinguístico; uma seção sobre a Língua Brasileira de Sinais; uma sobre Língua Portuguesa para Surdos, destacando o registro das línguas no Currículo Bilíngue e, por fim, um quadro síntese com os Conceitos Fundamentadores.

O documento, em suas concepções estruturantes, na Parte 2, declara como princípio o estabelecimento de uma base linguística e cognitiva consistente na Libras como fundamento para a promoção do aprendizado da segunda língua, com especial atenção para a metalinguagem. O documento destaca, também que embora a proposição seja de fundamentar o domínio da Libras para o ensino de Língua Portuguesa de forma que o conhecimento dessas línguas estejam suficientemente articulado, com antecipação da exposição e análise da Libras para subsequente exercício na Língua Portuguesa, não há a subserviência de uma a outra, com efeito, a Libras não está a serviço da Língua Portuguesa mas compõe a base para o desenvolvimento bilíngue do surdo.

A Parte 3 sistematiza os objetivos de aprendizagem e desenvolvimento do currículo. É neste momento que o projeto efetivo do currículo se concretiza numa proposição apresentando "o que cada estudante precisa aprender a cada ano e Ciclo" (SME-SP, 2019a, p. 60), definindo essas proposições como "objetivos de aprendizagem e desenvolvimento". Estes objetivos são organizados em "objetos de conhecimento" que "indicam o que os professores precisam ensinar a cada ciclo" e que, por sua vez, são organizados em "eixos estruturantes" (SME-SP, 2019a, p. 60). 
Este trabalho segue na apresentação de uma análise dos objetivos de aprendizagem e desenvolvimento apresentados nos documentos em questão. Propõe-se a análise desses objetivos em suas relações com as habilidades de expressão ou compreensão de narrativas que mobilizam, de forma explícita ou não. De fato, o uso da língua (de sinais ou oral) se dá na interação entre as pessoas e narrar algo é um ponto central dessas interações. Para este momento serão observados as menções diretas a termos como narrativa, narrar, observar histórias, contar histórias, produzir etc., além das habilidades linguísticas precursoras para o contato comunicativo.

\section{Narrativas e os objetivos de aprendizagem e desenvolvimento no currículo de Libras}

Organizado em um eixo único para a Educação Infantil chamado "Bases Precursoras para a Aquisição da Língua de Sinais", os objetivos de aprendizagem e desenvolvimento são organizados em três objetos de conhecimento: visualidade, organização linguístico-motora, e compreensão e interação. No Ensino Fundamental, são propostos os eixos "uso da língua de sinais", "identidade surda", "prática da análise linguística" e "literatura surda". O Currículo da Cidade - Língua Brasileira de Sinais apresenta 554 objetivos de aprendizagem e desenvolvimento distribuídos na Educação Infantil e nos três ciclos do Ensino Fundamental.

A Educação Infantil no Currículo da Cidade - Língua Brasileira de Sinais é vista como um momento que proporciona a oportunidade para a aquisição da Libras pela criança surda. Considerando que mais de 90\% das crianças surdas nascem em famílias são ouvintes (QUADROS, 1997) e, consequência deste fato, a criança entrará em contato com a língua de sinais ao entrar na escola, o currículo propõe para este nível o desenvolvimento das habilidades precursoras para a aquisição da língua. De acordo com a Parte 2 do currículo, a defesa para esta atenção especial à aquisição da Libras baseia-se na necessidade de uma estrutura linguística acessível para elaborar/organizar a cognição da criança surda para seu desenvolvimento pleno e, também, para que posteriormente possa aprender uma segunda língua.

Os objetos de conhecimento na Educação Infantil têm como propósito a potencialização de habilidades de atenção e percepção visual, desenvolvimento e refinamento motor e interação comunicativa. Os professores e instrutores surdos e professores bilíngues, serão os modelos linguísticos para essas crianças e, por isso, presume-se a presença de profissionais fluentes em Libras.

Habilidades como a de contar histórias, o reconto, a observação de livros infantis sinalizados, dentre outras, estão presentes nos objetivos de aprendizagem e desenvolvimento para a Educação Infantil, possuindo papel fundamental para a ampliação de vocabulário e buscando o estabelecimento de um arcabouço linguístico consistente. Exemplos de proposições que abordam as habilidades são os objetivos "2.9. Observar histórias infantis sinalizadas (SME-SP, 2019a, p. 108)" e "3.15. Explorar atividades com histórias sinalizadas em sequência temporal (figuras)." (SME-SP, 2019a, p. 109), atividades constantes no dia a dia escolar, através da roda de história e que exploram a compreensão de narrativas e o contato com estímulos visuais que dão suporte à construção de repertório e organização de eventos em narrativas. Os verbos cruciais na Educação Infantil são "explorar", "usar", "observar" e "compreender", sugerindo a procura de objetivos com predominância da ordem da compreensão da língua e da exploração para sua posterior produção.

A Tabela 1, a seguir resume as informações sobre o número de objetivos de aprendizagem e desenvolvimento no Currículo da Cidade - Libras, para a Educação Infantil. A distribuição do número de objetivos por objeto de conhecimento é uniforme. A última coluna da direita indica a porcentagem de objetivos de aprendizagem e desenvolvimento que se relacionam de forma direta com habilidades narrativas. A abordagem de habilidades da ordem do narrar também se distribui de forma equilibrada entre os objetos de conhecimento e ocupam $22 \%$ do total dos objetivos de aprendizagem e desenvolvimento. 
Tabela 1 - Objetivos de Aprendizagem e Desenvolvimento no Currículo da Cidade Língua Brasileira de Sinais - Educação Infantil

\begin{tabular}{|c|c|c|c|c|}
\hline \multicolumn{5}{|c|}{ Currículo da Cidade - Língua Brasileira de Sinais - Educação Infantil } \\
\hline \multirow{2}{*}{ Eixos Estruturantes } & Objetos de Conhecimento & $\begin{array}{c}\text { Objetivos de } \\
\text { Aprendizagem e } \\
\text { Desenvolvimento }\end{array}$ & $\begin{array}{c}\text { Objetivos } \\
\text { relacionados } \\
\text { a narrativa }\end{array}$ & $\%$ \\
\hline \multirow{2}{*}{$\begin{array}{c}\text { Bases Precursoras da } \\
\text { Aquisição da Língua de Sinais }\end{array}$} & Visualidade & 10 & 2 & 20 \\
\cline { 2 - 5 } & Organização Linguístico-motora & 10 & 2 & 20 \\
\cline { 2 - 5 } & Compreensão e Interação & 16 & 4 & 25 \\
\hline Total Língua Portuguesa para Surdos - Ciclo Alfabetização & 36 & 8 & 22 \\
\hline
\end{tabular}

O Ciclo de Alfabetização engloba os três primeiros anos do ensino fundamental e requer, como peça fundamental, a presença do adulto surdo e do professor bilíngue fluente. Estes educadores suprem a necessidade do estudante surdo figurando como apoio, modelo e pares linguísticos avançados para a continuidade da aquisição da língua de sinais. O desenvolvimento pode ser desencadeado com isso proporciona ao estudante alcançar diversos objetivos de aprendizagem e desenvolvimento, como o de utilizar a Libras para acompanhar com atenção as histórias contadas, para contar histórias e fazer relatos com sequência temporal, para antecipação de fatos, para fazer uso de expressões faciais e corporais, utilizar o sistema de pronominalização da Libras, assim como diversos recursos que os tornem aptos às interações linguísticas e para a reflexão sobre a sua língua. Um objetivo de aprendizagem e desenvolvimento exemplifica isso ao propor "participar de momentos de diálogos para o compartilhamento de vivências, compartilhamento de repertório cultural e de emoções com os interlocutores." (SME-SP, 2019a, p. 115) mobiliza as habilidades narrativas que requerem as diversas habilidades citadas no parágrafo anterior e de forma naturalística, por exemplo, em rodas de conversa e relatos de fim de semana.

À contação de histórias, uma das formas mais eficazes para o trabalho com línguas de sinais é apresentada, paulatinamente, o trabalho com uso da prosódia na Libras onde, são enfatizados os aspectos não manuais e os mecanismos de flexão de gênero e número, levando os estudantes a reconhecer os elementos de uma narrativa de forma explícita, com objetivos de aprendizagem e desenvolvimento que constam no eixo estruturante de análise linguística. A partir dos modelos linguísticos, o estudante inicia o desenvolvimento de suas habilidades narrativas respeitando o turno comunicativo e aptos a observar as intenções nos enunciados. A proposta neste ciclo é de que o estudante alcance domínio morfossintático, apresentando expressões faciais e corporais da Libras, explorando a compreensão e produção sinalizada, mantendo a sequência lógico-temporal, reconhecendo as características dos personagens e observando a adequação do uso sistema de pronominalização. 0 estudante é então, incentivado a produzir discursos descritivos bem como a expor suas idéias, defendendo-as e justificando sua posição. 
Tabela 2 - Objetivos de Aprendizagem e Desenvolvimento nos Ciclo: Narrativas no Currículo da Cidade Língua Brasileira de Sinais - Ciclo Alfabetização

\begin{tabular}{|c|c|c|c|c|}
\hline \multicolumn{5}{|c|}{ Currículo da Cidade - Língua Brasileira de Sinais - Ciclo Alfabetização } \\
\hline Eixos Estruturantes & Objetos de Conhecimento & $\begin{array}{l}\text { Objetivos de } \\
\text { Aprendizagem e } \\
\text { Desenvolvimento }\end{array}$ & $\begin{array}{l}\text { Objetivos } \\
\text { relacionados } \\
\text { a narrativa }\end{array}$ & $\%$ \\
\hline \multirow{3}{*}{$\begin{array}{l}\text { Uso da Língua } \\
\text { de Sinais }\end{array}$} & Bases da Exploração da Visualidade & 13 & 3 & 23 \\
\hline & Compreensão e Produção & 26 & 16 & 61 \\
\hline & Comunicação e Interação & 19 & 7 & 37 \\
\hline \multirow{3}{*}{ Identidade Surda } & Cultura Surda & 32 & 1 & 3 \\
\hline & Interculturalidade & 7 & 0 & 0 \\
\hline & Histórias das Comunidades Surdas & 8 & 1 & 12 \\
\hline \multirow{4}{*}{ Análise Linguística } & Aspectos Fonético-Fonológicos & 12 & 0 & 0 \\
\hline & Campos Semânticos & 9 & 0 & 0 \\
\hline & Sintaxe da Libras & 14 & 1 & 7 \\
\hline & Coerência Discursiva & 15 & 14 & 93 \\
\hline \multirow{2}{*}{ Literatura Surda } & Apreciação Estética & 25 & 17 & 68 \\
\hline & Produção Artístico Literária & 12 & 5 & 41 \\
\hline \multicolumn{2}{|c|}{ Total Língua Brasileira de Sinais - Ciclo Alfabetização } & 192 & 65 & 34 \\
\hline
\end{tabular}

A abrangência dos objetivos de aprendizagem e desenvolvimento pode ser observada na Tabela 2, na coluna correspondente aos Objetos de Conhecimento. Os objetos de conhecimento que mais mobilizaram habilidades narrativas forma "Bases da Exploração da Visualidade", "Compreensão e Produção", "Histórias das Comunidades Surdas", "Coerência Discursiva", "Apreciação Estética" e "Produção Artístico Literária", com um total de 34\% dos objetivos de aprendizagem e desenvolvimento propostos relacionados a habilidades narrativas.

Ao iniciar o Ciclo Interdisciplinar, espera-se que o estudante surdo deva apresentar domínio no uso da Libras, desenvolvendo sua capacidade interacional, de compreensão e produção, para a construção de seus conhecimentos metalinguísticos.

Assim sendo, o documento propõe que as narrativas elaboradas pelos estudantes já apresentem características gramaticais consolidadas, com o uso do espaço de sinalização e da sintaxe da língua, assim com de expressões corporais associadas, com organização discursiva nas expressões de causalidade. O domínio explícito dessas características é proposto nos objetivos que compõem o eixo estruturante "uso da língua de sinais", em conjunto com "análise linguística". São propostas, também, a modificação do discurso de acordo com pistas pragmáticas na interação, propondo o domínio do registro linguístico a depender das reações interlocutor. 
De acordo com o documento, ao final deste ciclo o estudante deverá estar apto a reconhecer os comportamentos linguísticos em ambientes e situações formais e informais e a produzir textos espontâneos em Libras. Deverá, também, ter condições de explorar itens da gramática da língua como os advérbios de lugar, de tempo e de intensidade, o processo anafórico, a simultaneidade, os classificadores e o uso do espaço com auxílio do professor. O conhecimento metalinguístico requerido também exige a compreensão dos verbos, dos substantivos, dos adjetivos, das marcações de número, entre outros (conforme objetivo "Utilizar o processo anafórico, simultaneidade, classificadores e o uso do espaço na elaboração do discurso" (SME-SP, 2019a, p. 135).

Além desse exemplo, diversos objetivos elencados propõem habilidades imprescindíveis para o desenvolvimento da habilidade narrativa, como a identificação da ordem básica das sentenças em Libras em vídeos ou escrita de sinais, objetivo que favorece a produção de textos sinalizados autorais individualmente ou coletivamente, a proposição do exercício de discursos descritivos apresentando expressões de causalidade e condições entre ideias ou a escolha dos sinais a serem usados para atingir o sentido desejado.

Tabela 3 - Objetivos de Aprendizagem e Desenvolvimento nos Ciclo: Narrativas no Currículo da Cidade Língua Brasileira de Sinais - Ciclo Interdisciplinar

\begin{tabular}{|c|c|c|c|c|}
\hline \multicolumn{5}{|c|}{ Currículo da Cidade - Língua Brasileira de Sinais - Ciclo Interdisciplinar } \\
\hline Eixos Estruturantes & Objetos de Conhecimento & $\begin{array}{c}\text { Objetivos de } \\
\text { Aprendizagem e } \\
\text { Desenvolvimento }\end{array}$ & $\begin{array}{l}\text { Objetivos } \\
\text { relacionados } \\
\text { a narrativa }\end{array}$ & $\%$ \\
\hline \multirow{4}{*}{$\begin{array}{l}\text { Uso da Língua } \\
\text { de Sinais }\end{array}$} & Compreensão e Produção Sinalizada & 47 & 32 & 68 \\
\hline & Interação/Conversação & 10 & 0 & 0 \\
\hline & Uso Formal e Informal da Língua & 11 & 8 & 73 \\
\hline & Conhecimento de Mundo & 10 & 4 & 4 \\
\hline \multirow{3}{*}{ Identidade Surda } & História do Surdo no Brasil & 10 & 0 & 0 \\
\hline & Cultura Surda & 14 & 0 & 0 \\
\hline & Acessibilidade na Comunicação & 10 & 0 & 0 \\
\hline \multirow{4}{*}{ Análise Linguística } & Aspectos Fonético-Fonológicos & 14 & 0 & 0 \\
\hline & Aspectos Morfológicos & 17 & 1 & 6 \\
\hline & Sintaxe da Libras & 12 & 1 & 8 \\
\hline & Semântica da Libras & 9 & 0 & 0 \\
\hline \multirow{2}{*}{ Literatura Surda } & Apreciação Estética & 9 & 0 & 0 \\
\hline & Produção Artístico Literária & 21 & 8 & 38 \\
\hline \multicolumn{2}{|c|}{ Total Língua Brasileira de Sinais - Ciclo Interdisciplinar } & 194 & 54 & 28 \\
\hline
\end{tabular}


A Tabela 3 mostra que $28 \%$ dos objetivos de aprendizagem e desenvolvimento propostos no Ciclo Interdisciplinar possuem relação com o desenvolvimento de habilidades narrativas com destaque para os objetos de conhecimento "Compreensão e Produção Sinalizada", "Uso Formal e Informal da Língua" e "Produção Artístico Literária".

No Ciclo Autoral, os objetivos de aprendizagem e desenvolvimento se apresentam para aprofundar e consolidar o domínio da língua de sinais pelo estudante. O verbo "utilizar" predomina nos objetivos, como em "utilizar os turnos comunicativos e recursos discursivos para iniciar, manter e finalizar um discurso" (SME-SP, 2019a, p. 159) e "compreender e utilizar figuras de linguagem na Libras (SME-SP, 2019a, p. 157)". Este ciclo requer que o estudante utilize a Libras com clareza e consciência em suas práticas discursivas sendo capaz de argumentar apresentando seu posicionamento e justificando suas ideias por um discurso, tanto formal quanto informal, com coesão e coerência, aplicando termos comunicativos e recursos discursivos na manutenção de um discurso. Esse domínio é previsto pelos objetivos apresentados no ciclo anterior e que, neste momento, são consolidados.

Tabela 4 - Objetivos de Aprendizagem e Desenvolvimento nos Ciclo: Narrativas no Currículo da Cidade Língua Brasileira de Sinais - Ciclo Autoral

\begin{tabular}{|c|c|c|c|c|}
\hline \multicolumn{5}{|c|}{ Currículo da Cidade - Língua Brasileira de Sinais - Ciclo Autoral } \\
\hline Eixos Estruturantes & Objetos de Conhecimento & $\begin{array}{c}\text { Objetivos de } \\
\text { Aprendizagem e } \\
\text { Desenvolvimento }\end{array}$ & $\begin{array}{l}\text { Objetivos } \\
\text { relacionados } \\
\text { a narrativa }\end{array}$ & $\%$ \\
\hline \multirow{3}{*}{$\begin{array}{l}\text { Uso da Língua } \\
\text { de Sinais }\end{array}$} & Compreensão e Produção Sinalizada & 28 & 16 & 57 \\
\hline & Interação/Conversação & 7 & 0 & 0 \\
\hline & Uso Formal e Informal da Língua & 8 & 7 & 87 \\
\hline \multirow{4}{*}{ Identidade Surda } & Políticas para a Comunidade Surda & 7 & 0 & 0 \\
\hline & Comunidades Surdas no Mundo & 6 & 0 & 0 \\
\hline & Cultura Surda & 15 & 0 & 0 \\
\hline & Acessibilidade na Comunicação & 8 & 0 & 0 \\
\hline \multirow{4}{*}{ Análise Linguística } & Sintaxe da Libras & 13 & 0 & 0 \\
\hline & Semântica da Libras & 9 & 0 & 0 \\
\hline & Pragmática & 5 & 0 & 0 \\
\hline & Estrutura do Texto & 6 & 6 & 100 \\
\hline \multirow{2}{*}{ Literatura Surda } & Apreciação Estética & 9 & 6 & 67 \\
\hline & Produção Artístico Literária & 11 & 8 & 73 \\
\hline \multicolumn{2}{|c|}{ Total Língua Brasileira de Sinais - Ciclo Autoral } & 132 & 43 & 32 \\
\hline
\end{tabular}


As habilidades narrativas no Ciclo Autoral recebem uma atenção metalinguística especial. A Tabela 4 mostra que, além dos objetos de conhecimento "Compreensão e Produção Sinalizada", "Uso Formal e Informal da Língua" e "Produção Artístico Literária" que já apresentam mobilização de habilidades narrativas nos ciclos anteriores, figuram "Estrutura do Texto" e "Apreciação Estética" como objetos de conhecimento que propõem a análise de narrativas da Libras e a discussão dessa análise. Neste ciclo, 32\% dos objetivos de aprendizagem e desenvolvimento são dedicados, de forma direta ou indireta, às habilidades narrativas.

\section{Narrativas e os objetivos de aprendizagem e desenvolvimento no currículo de língua portuguesa para surdos}

O Currículo da Cidade - Língua Portuguesa para Surdos é organizado nos eixos "prática de leitura de textos", "produção sinalizada", "prática de análise linguística", "prática de produção de textos escritos" e "dimensão intercultural", apresentando 772 objetivos de aprendizagem e desenvolvimento distribuídos nos três ciclos do Ensino Fundamental. O documento prevê que o estudante ingresse no $1^{\circ}$ ano do Ensino Fundamental com conhecimentos suficientes na Libras para ter início o aprendizado da segunda língua, Língua Portuguesa, usando recursos de metalinguagem.

O Ciclo de Alfabetização no Currículo de Língua Portuguesa para Surdos apresenta-se como o momento da aquisição do sistema alfabético, por meio do reconhecimento do alfabeto, com a exploração de capas de livros, nomes em listas, da localização do nome próprio, leitura de palavras simples, entre outros. Em todo o Ensino Fundamental é usada a primeira língua como língua de instrução e Língua Portuguesa vai, portanto, sendo acomodada ao conhecimento subsidiado pela língua de sinais.

O documento prevê a antecipação de conteúdos no Currículo de Libras para que o estudante já tenha consciência, na Libras, de termos e conteúdos a serem explorados na Língua Portuguesa. Os verbos primordiais nesse período são "reconhecer", "conhecer" e "compreender", com o uso de narrativas sempre na Libras.

Os objetivos propostos colocam o professor como o escriba e mediador do contato inicial com o registro escrito da Língua Portuguesa. A sinalização parece estar presente como um recurso cultural e cognitivo para a elaboração de conhecimento a partir do contato com o material escrito. Os textos são produzidos de forma coletiva sem que inda se proponha autonomia na produção textual. O contraste linguístico é um objeto de conhecimento muito importante nessa fase. No eixo prática de produção de textos escritos há o objeto de conhecimento "Capacidades de aquisição do sistema de escrita alfabético" que permanece nos três anos do ciclo de alfabetização. Há um fortalecimento do estudante surdo como sujeito sociocultural e a percepção das diferenças culturais entre surdos e ouvintes.

Gradativamente surgem os verbos "ler", "produzir", "participar" e "articular". No caso do verbo "produzir", temos o objetivo "produzir relatos escritos de experiências vividas, tendo o professor como escriba, a partir da Libras." (SME-SP, 2019b, p. 117), objetivo que pode ser abordado no relato de final de semana feito em roda de conversa, com o professor elaborando o registro escrito na lousa e os estudantes contribuindo com informações. No último ano do ciclo de alfabetização, o estudante surdo apoia-se em recursos multimodais e no relato do professor para sua produção, mas caminha para as primeiras produções autônomas com aprofundamento progressivo para cada ano. 
Tabela 5 - Objetivos de Aprendizagem e Desenvolvimento nos Ciclo: Narrativas no Currículo da Cidade Língua Portuguesa para Surdos - Ciclo Alfabetização

\begin{tabular}{|c|c|c|c|c|}
\hline \multicolumn{5}{|c|}{ Currículo da Cidade - Língua Portuguesa para Surdos - Ciclo Alfabetização } \\
\hline Eixos Estruturantes & Objetos de Conhecimento & $\begin{array}{l}\text { Objetivos de } \\
\text { Aprendizagem e } \\
\text { Desenvolvimento }\end{array}$ & $\begin{array}{l}\text { Objetivos } \\
\text { relacionados } \\
\text { a narrativa }\end{array}$ & $\%$ \\
\hline \multirow{6}{*}{$\begin{array}{l}\text { Prática de Leitura } \\
\text { de Textos }\end{array}$} & $\begin{array}{l}\text { Capacidades de Aquisição do } \\
\text { Sistema de Escrita Alfabética } \\
\text { (Compreensão) }\end{array}$ & 27 & 3 & 11 \\
\hline & Literatura Surda & 6 & 4 & 67 \\
\hline & Estratégias de Leitura & 27 & 16 & 59 \\
\hline & Procedimentos de Leitura & 17 & 6 & 35 \\
\hline & Comportamentos de Leitura & 9 & 0 & 0 \\
\hline & \begin{tabular}{|c|} 
Capacidades de Apreciação e \\
Réplica do Leitor em Relação ao Texto \\
\end{tabular} & 11 & 10 & 91 \\
\hline \multirow{2}{*}{ Produção Sinalizada } & Interação Discursiva & 19 & 10 & 52 \\
\hline & $\begin{array}{l}\text { Capacidades de Produção e } \\
\text { Sinalização de Textos }\end{array}$ & 9 & 7 & 78 \\
\hline \multirow{6}{*}{$\begin{array}{l}\text { Prática de Análise } \\
\text { Linguística }\end{array}$} & \begin{tabular}{|c|} 
Comportamento Relativo à Prática de \\
Análise Linguística \\
\end{tabular} & 3 & 0 & 0 \\
\hline & Características dos Gêneros e Textos & 19 & 13 & 68 \\
\hline & $\begin{array}{l}\text { Aspectos Gráficos Textuais/ } \\
\text { Multimodais }\end{array}$ & 6 & 2 & 33 \\
\hline & Aspectos Lexicais e Semânticos & 28 & 0 & 0 \\
\hline & Coesão e Coerência & 5 & 2 & 40 \\
\hline & Contraste Linguístico & 12 & 1 & 8 \\
\hline \multirow[t]{2}{*}{$\begin{array}{l}\text { Prática de Produção } \\
\text { de Textos Escritos }\end{array}$} & $\begin{array}{l}\text { Capacidades de Aquisição do } \\
\text { Sistema de Escrita Alfabética } \\
\text { (Expressão) }\end{array}$ & 17 & 0 & 0 \\
\hline & Capacidade de Produção de Textos & 15 & 10 & 67 \\
\hline $\begin{array}{l}\text { Dimensão } \\
\text { Intercultural }\end{array}$ & Identidade e Cultura Surda & 19 & 4 & 21 \\
\hline \multicolumn{2}{|c|}{ Total Língua Portuguesa para Surdos - Ciclo Alfabetização } & 249 & 88 & 35 \\
\hline
\end{tabular}

A Tabela 5 mostra que 35\% dos objetivos de aprendizagem e desenvolvimento presentes no Ciclo de Alfabetização do Currículo de Língua Portuguesa para Surdos estão relacionados às habilidades narrativas, especificamente em Libras. Destacam-se os objetos de conhecimento "Literatura Surda", "Estratégias de Leitura", "Procedimentos de Leitura", Interação Discursiva", "Capacidades de Produção e Sinalização de Textos" e "Capacidade de Produção de Textos". 
Tabela 6 - Objetivos de Aprendizagem e Desenvolvimento nos Ciclo: Narrativas no Currículo da Cidade Língua Portuguesa para Surdos - Ciclo Interdisciplinar

\begin{tabular}{|c|c|c|c|c|}
\hline \multicolumn{5}{|c|}{ Currículo da Cidade - Língua Portuguesa para Surdos - Ciclo Interdisciplinar } \\
\hline Eixos Estruturantes & Objetos de Conhecimento & $\begin{array}{c}\text { Objetivos de } \\
\text { Aprendizagem e } \\
\text { Desenvolvimento }\end{array}$ & $\begin{array}{l}\text { Objetivos } \\
\text { relacionados } \\
\text { a narrativa }\end{array}$ & $\%$ \\
\hline \multirow{5}{*}{$\begin{array}{c}\text { Prática de Leitura } \\
\text { de Textos }\end{array}$} & Literatura Surda & 8 & 5 & 62 \\
\hline & Estratégias de Leitura & 29 & 6 & 21 \\
\hline & Procedimentos de Leitura & 3 & 0 & 0 \\
\hline & Comportamentos de Leitura & 12 & 4 & 33 \\
\hline & $\begin{array}{l}\text { Capacidades de Apreciação e } \\
\text { Réplica do Leitor em Relação ao Texto }\end{array}$ & 24 & 9 & 37 \\
\hline Produção Sinalizada & Interação Discursiva & 48 & 35 & 73 \\
\hline \multirow{11}{*}{$\begin{array}{c}\text { Prática de Análise } \\
\text { Linguística }\end{array}$} & $\begin{array}{c}\text { Comportamento Relativo à Prática de } \\
\text { Análise Linguística }\end{array}$ & 3 & 0 & 0 \\
\hline & Características dos Gêneros e Textos & 12 & 6 & 50 \\
\hline & $\begin{array}{l}\text { Aspectos Gráficos Textuais/ } \\
\text { Multimodais }\end{array}$ & 3 & 2 & 67 \\
\hline & Aspectos Lexicais e Semânticos & 11 & 4 & 36 \\
\hline & Coesão e Coerência & 18 & 7 & 39 \\
\hline & Contraste Linguístico & 2 & 0 & 0 \\
\hline & Segmentação & 6 & 0 & 0 \\
\hline & Morfologia & 14 & 0 & 0 \\
\hline & Sintaxe & 2 & 0 & 0 \\
\hline & Variação Linguística & 5 & 3 & 60 \\
\hline & Ortografia na Intermodalidade & 3 & 0 & 0 \\
\hline $\begin{array}{l}\text { Prática de Produção } \\
\text { de Textos Escritos }\end{array}$ & Capacidade de Produção de Textos & 38 & 9 & 23 \\
\hline $\begin{array}{l}\text { Dimensão } \\
\text { Intercultural }\end{array}$ & Identidade e Cultura Surda & 15 & 5 & 33 \\
\hline \multicolumn{2}{|c|}{ Total Língua Portuguesa para Surdos - Ciclo Interdisciplinar } & 256 & 95 & 37 \\
\hline
\end{tabular}

Os objetivos de aprendizagem e desenvolvimento propostos para Ciclo Interdisciplinar pressupõe um estudante que domina o sistema alfabético. Ainda há predominância do registro coletivo e em grupo, em detrimento da produção escrita autônoma. Os objetivos com produção autônoma ampliada começam a aparecer em produções de textos, entrevistas, instruções de jogos, anotações, reconto de histórias, escrita de diários e revisões textuais. Estes objetivos com interação com o educador, o que exibe a presença de atividade dialógica e mobilizadora de habilidades narrativas em seus escopos. 
Como exemplo de reconto temos objetivo "recontar histórias conhecidas, respeitando as características do gênero e utilizando, progressivamente, as marcas do registro literário escrito" (SME-SP, 2019b. p. 138). O último ano do ciclo interdisciplinar traz sérias mudanças. É o início do Ensino Fundamental II, com a presença de vários professores especialistas e época de amadurecimento dos estudantes.

De acordo com a Tabela 6, 37\% dos objetivos de aprendizagem e desenvolvimento propostos para o Ciclo Interdisciplinar estão relacionados à habilidades narrativas. Os objetos de conhecimento "Literatura Surda", "Interação Discursiva" e "Aspectos Gráficos Textuais/Multimodais" são os que mais mobilizam essas habilidades. Os objetivos de aprendizagem e desenvolvimento presentes nesses objetos de conhecimento possuem caráter dialógico e discursivo na Libras com vistas à compreensão da Língua Portuguesa, acentuando o protagonismo da língua de sinais na construção do conhecimento da segunda língua.

Tabela 7 - Objetivos de Aprendizagem e Desenvolvimento nos Ciclo: Narrativas no Currículo da Cidade Língua Portuguesa para Surdos - Ciclo Autoral

\begin{tabular}{|c|c|c|c|c|}
\hline \multicolumn{5}{|c|}{ Currículo da Cidade - Língua Portuguesa para Surdos - Ciclo Autoral } \\
\hline Eixos Estruturantes & Objetos de Conhecimento & $\begin{array}{c}\text { Objetivos de } \\
\text { Aprendizagem e } \\
\text { Desenvolvimento }\end{array}$ & $\begin{array}{l}\text { Objetivos } \\
\text { relacionados } \\
\text { a narrativa }\end{array}$ & $\%$ \\
\hline \multirow{5}{*}{$\begin{array}{l}\text { Prática de Leitura } \\
\text { de Textos }\end{array}$} & Literatura Surda & 6 & 3 & 50 \\
\hline & Estratégias de Leitura & 34 & 10 & 29 \\
\hline & Procedimentos de Leitura & 6 & 0 & 0 \\
\hline & Comportamentos de Leitura & 18 & 2 & 11 \\
\hline & $\begin{array}{c}\text { Capacidades de Apreciação e } \\
\text { Réplica do Leitor em Relação ao Texto }\end{array}$ & 30 & 17 & 56 \\
\hline Produção Sinalizada & Interação Discursiva & 33 & 26 & 79 \\
\hline \multirow{11}{*}{$\begin{array}{c}\text { Prática de Análise } \\
\text { Linguística }\end{array}$} & $\begin{array}{c}\text { Comportamento Relativo à Prática de } \\
\text { Análise Linguística }\end{array}$ & 6 & 0 & 0 \\
\hline & Características dos Gêneros e Textos & 8 & 0 & 0 \\
\hline & $\begin{array}{l}\text { Aspectos Gráficos Textuais/ } \\
\text { Multimodais }\end{array}$ & 12 & 3 & 25 \\
\hline & Aspectos Lexicais e Semânticos & 9 & 5 & 55 \\
\hline & Coesão e Coerência & 9 & 5 & 55 \\
\hline & Contraste Linguístico & 21 & 1 & 5 \\
\hline & Segmentação & 15 & 0 & 0 \\
\hline & Morfologia & 14 & 0 & 0 \\
\hline & Sintaxe & 4 & 0 & 0 \\
\hline & Variação Linguística & 3 & 0 & 0 \\
\hline & Ortografia na Intermodalidade & 3 & 0 & 0 \\
\hline $\begin{array}{l}\text { Prática de Produção } \\
\text { de Textos Escritos }\end{array}$ & Capacidade de Produção de Textos & 22 & 7 & 32 \\
\hline $\begin{array}{l}\text { Dimensão } \\
\text { Intercultural }\end{array}$ & Identidade e Cultura Surda & 13 & 3 & 23 \\
\hline \multicolumn{2}{|c|}{ Total Língua Portuguesa para Surdos - Ciclo Autoral } & 266 & 82 & 31 \\
\hline
\end{tabular}


No ciclo autoral os objetivos propõem uma maior autonomia do estudante, com capacidade para editar o próprio texto, produzir crônicas e comentários em plataformas digitais, como pode ser observado no objetivo "escrever comentários em plataformas digitais para textos lidos, estabelecendo relação entre o texto e o comentário produzido." É possível observar que este objetivo exige que exista uma relação dialógica para sua concretização. Um exemplo prático desse objetivo de aprendizagem é fazer um comentário sobre um livro lido, ou sobre o autor no site da editora, o que exigirá uma discussão prévia sobre o que se vai comentar, sobre o teor do comentário e sobre os procedimentos para a realização de um comentário digital. Nos anos seguintes as produções aumentam em complexidade culminando com a produção dos gêneros carta de reclamação, carta ao leitor e biografia.

Neste ciclo as habilidades narrativas mobilizam um menor número de objetivos de aprendizagem e desenvolvimento. A Tabela 7 mostra que 31\% dos objetivos possuem relação direta ou indireta com habilidades narrativas. Trata-se de um ciclo final em que o estudante começa a migrar da produção realizada com a tutela do educador e da língua de sinais para uma produção independente e autônoma.

\section{Algumas considerações sobre o currículo bilíngue e as narrativas}

A Tabela 8 a seguir apresenta o total e a porcentagem de objetivos de aprendizagem e desenvolvimento que contemplam habilidades narrativas no Currículo Bilíngue. Os dados mostram uma distribuição homogênea entre os dois documentos, com 31\% dos objetivos de aprendizagem e desenvolvimento no Currículo de Língua de Sinais e 34\% no Currículo de Língua Portuguesa para Surdos, ressaltando que neste último há um eixo específico denominado "Produção Sinalizada" que prevê o uso de Libras para o ensino da Língua Portuguesa.

Tabela 8 - Objetivos de Aprendizagem e Desenvolvimento no Currículo Bilíngue

\begin{tabular}{|c|c|c|c|c|}
\cline { 2 - 5 } \multicolumn{1}{c|}{} & \multicolumn{2}{c|}{ Libras } & \multicolumn{2}{c|}{ Língua Portuguesa para Surdos } \\
\cline { 2 - 5 } & OAD propostos & $\begin{array}{c}\text { Relacionados } \\
\text { a narrativa }\end{array}$ & OAD propostos & $\begin{array}{c}\text { Relacionados } \\
\text { a narrativa }\end{array}$ \\
\hline Educação Infantil & 36 & $22 \%$ & - & - \\
\hline Ciclo Alfabetização & 192 & $34 \%$ & 249 & $35 \%$ \\
\hline Ciclo Interdisciplinar & 194 & $28 \%$ & 266 & $37 \%$ \\
\hline Ciclo Autoral & 132 & $32 \%$ & 771 & $31 \%$ \\
\hline Total & 554 & $31 \%$ & & $34 \%$ \\
\hline
\end{tabular}

As habilidades narrativas são essenciais para a aquisição e desenvolvimento da linguagem e envolvem domínios cognitivos gerais e específicos da língua (EISENBERG, 1985; PETERSON; MCCABE, 1990; RATHMANN et al., 2007), de forma que pode ser mobilizada em diversas (senão a maioria das) atividades, contemplando muitos objetivos de aprendizagem e desenvolvimento. O Currículo Bilíngue para Surdos enfatiza isso quando mobiliza sua terça parte de proposições com objetivos que evocam a habilidade em questão. 
O percurso da organização dos objetivos de aprendizagem e desenvolvimento em objetos de conhecimento e eixos estruturantes também anuncia a centralidade da narrativa para atingir seus objetivos. Observando os eixos estruturantes e seus objetos de conhecimentos nas duas primeiras colunas das tabelas 1, 2 e 5, temos: para o Currículo de Língua Brasileira de Sinais, "Bases Precursoras da Aquisição da Língua de Sinais", "Uso da Língua de Sinais", "Identidade Surda", "Análise Linguística" e "Literatura Surda"; e para Língua Portuguesa para Surdos, "Prática de Leitura de Textos", "Produção Sinalizada", "Prática de Análise Linguística", "Prática de Produção de Textos Escritos" e "Dimensão Intercultural". São dez eixos estruturantes, dos quais sete dependem do desenvolvimento de habilidades narrativas e os outros três ("Análise Linguística", "Prática de Análise Linguística" e "Prática de Produção de Textos Escritos") dependem do desenvolvimento cognitivo que só pode ser alcançado com o desenvolvimento anterior alcançado.

O Currículo de Libras, portanto, antecipa esse desenvolvimento com seu início em momento anterior ao de Língua Portuguesa para Surdos e apresenta proposições de base, com compreensão e exploração para a aquisição da Libras e com estrutura baseada em objetos imprescindíveis para o desenvolvimento de habilidades narrativas. Trata-se uma proposição que mescla a interação e comunicação com o controle metalinguístico, pelo educador, de habilidades cognitivas que sustentarão a aquisição e o desenvolvimento da língua de sinais e de outras línguas que o estudante surdo vier a prender, conforme Quadros (1997), Lacerda e Mantelatto (2000) e Lodi et al. (2002).

Seguindo com os três ciclos do Ensino Fundamental, o documento explora o desenvolvimento da produção, com a presença dos interlocutores para o incremento das habilidades narrativas. Há o início do estudo metalinguístico da Libras, inicialmente por itens descritivos, mas paulatinamente se deslocando para a compreensão da estrutura e uso da língua de uma forma ampla preparando o estudante para o início do impacto maior nas metalinguagem para aprendizado da segunda língua, com o objeto de conhecimento "Contraste Linguístico" presente no Currículo de Língua Portuguesa para Surdos.

Este conhecimento metalinguístico, principalmente da gramática espacial da Libras e de seu uso (Pragmática) vão sendo aprofundados e o estudante começa a controlar sua sinalização a partir de recursos explícitos. Este ponto (explicitude do conhecimento metalinguístico na língua de sinais) é que permitirá, não apenas o manuseio da primeira língua, mas o acesso à segunda língua por contraste e reflexão sobre o contraste. De fato, o estudo da Língua Portuguesa por estudantes ouvintes é baseado no aprendizado da leitura e escrita, estudo da estrutura da língua e apreciação literária. Isso ocorre com o estudante ouvinte já com língua adquirida. Esta mesma lógica transparece nos documentos para o estudante surdo, mas fundamentando a Libras como primeira língua.

Os eixos estruturantes do Currículo de Língua Portuguesa também chamam atenção pela sua organização que parece pretender uma sequência. A prática de leitura de textos precede a produção sinalizada sugerindo o acesso ao registro escrito analisado e refletido pela língua de sinais, para posterior acionamento das práticas de análise linguística na Língua Portuguesa. O processo é tutelado pela língua de sinais e a Língua Portuguesa é fomentada pelo conhecimento linguístico e de mundo adquirido na primeira língua.

Para estudantes ouvintes, o ingresso na Educação Básica representa o início da alfabetização. Para os estudantes surdos, a partir do $1^{\circ}$ ano, eles começam o processo de aprendizado da Língua Portuguesa como primeira língua, o que requer uma série de procedimentos metodológicos e didáticos baseados em estudos da alfabetização.

O conceito de alfabetização focado no aprendizado de um sistema linguístico escrito para estu- 
dantes ouvintes, em sua primeira língua, é bastante discutido (SKLIAR-CABRAL, 2019; GONTIJO et al., 2020). Estudantes surdos, entretanto, não possuem acesso pleno à via auditiva e este fato limita a aquisição natural de uma língua oral, levando à necessidade de tratamento específico para seu aprendizado. Isso faz com que a Língua Portuguesa figure como ensino de segunda língua e, ainda, em uma modalidade que não permite ao surdo o acesso pleno. Por essa razão, o aprendizado da Língua Portuguesa residiria no campo do ensino de segunda língua, sendo o profissional especialista o mais adequado para o ensino de Língua Portuguesa para surdos, desde as séries iniciais.

A alfabetização em língua de sinais é sugerida pelo documento com o registro da língua de sinais usando, de forma alternativa, a escrita de sinais. Os documentos apresentam essa ideia defendendo a possibilidade de representação da consciência linguística visuoespacial da Libras (QUADROS, 1997; STUMPF, 2009; OLIVEIRA, 2012), a possibilidade de realizar a representação explícita da língua e o uso desta ferramenta como recurso para a análise linguística, provendo a redundância necessária para o exercício metalinguístico (SME-SP, 2019a, p. 98). Objetos de aprendizagem e desenvolvimento são sugeridos para este fim de forma discreta nos documentos.

O objetivo na conclusão do Ensino Fundamental é o desenvolvimento bilíngue do estudante surdo, com a aquisição plena da Libras e domínio metalinguístico de sua estrutura e com o desenvolvimento da leitura e escrita autônoma (em segunda língua, ressalta-se) até o $9^{\circ}$ ano. Além desses conhecimentos específicos das línguas, há previsão de conhecimento substancial sobre identidade, cultura surda, cultura ouvinte, interculturalidade e funções da linguagem - todos objetos que prescindem de habilidades narrativas e que constroem a alfabetização consistente nas duas línguas. Trata-se de um documento que propõe uma relação intrínseca entre uso e conhecimento das línguas, colocando a Libras como fundamento para a construção de outros conhecimentos e para o desenvolvimento integral do estudante.

\section{Referências}

BALBANI, Aracy P.S.; MONTOVANI, Jair C. Impacto das otites médias na aquisição da linguagem em crianças. J. Pediatr. (Rio J.), Porto Alegre, v. 79, n. 5, p. 391-396, Oct. 2003.

BISHOP, Dorothy. O desenvolvimento de linguagem em condições normais. In: MOGFORD, Kay; BISHOP, Dorothy (Orgs.), O desenvolvimento da linguagem em circunstâncias excepcionais. Rio de Janeiro: Revinter, 2002. p. 1-26.

BORGES, Lucivanda Cavalcante; SALOMAO, Nádia Maria Ribeiro. Aquisição da linguagem: considerações da perspectiva da interação social. Psicol. Reflex. Crit., Porto Alegre, v. 16, n. 2, p. 327-336, 2003.

BRITO, Lucinda Ferreira. Por uma gramática de Língua de Sinais. Rio de Janeiro: Tempo Brasileiro, 1995. 273p.

BUSSMANN, Hadumod. Routledge Dictionary of Language and Linguistics. Translated and edited by Gregory P. Trauth and Kerstin Kazzazi. London: Routledge. 1999. 1304p.

DOLL JR.; William E. Currículo: uma perspectiva pós-moderna. Tradução de Maria Adriana Veríssimo Veronese. Porto Alegre: Artes Médicas, 1997. 224p.

EISENBERG, A.R. Learning to describe past experiences in conversation. Discourse Processes, v. 8, p. 177-204, 1985.

GONTIJO, Cláudia Maria Mendes; COSTA, Dania Monteiro Vieira; PEROVANO, Nayara Santos. Alfabetização na Base Nacional Comum Curricular (BNCC). Pro-Posições[online], v.31, 2020. Available from <http://www.scielo. br/scielo.php?script=sci_arttext\&pid=S010373072020000100511\&lng=en\&nrm=is> access on 01 June 2020. 
HERMAN, Rosalind; GROVE, N.; HOLMES, Sallie; MORGAN, Gary; SUTHERLAND, Hilary; WOLL, Bencie. Assessing British Sign Language Development: Production Test (Narrative skills). London: City University, 2004.

HORTA, Adriana; BARBOSA, Felipe Venâncio; GARGALAKA, Mônica Conforto; ESPÍRITO SANTO, Roseli Gonçalves; DRAGO, Silvana Lucena dos Santos; GARCIA, Mônica Leone. O protagonismo surdo na construção do currículo bilíngue. Magistério, n. 7. São Paulo: SME / COPED, 2020.

HUDSON, J.A.; SHAPIRO, C.R. From knowing to telling: the development of children's scripts, stories and personal narratives. In: MCCABE, A; PETERSON, C. (Eds.), Developing narrative structure. Hillsdale, NJ: Lawrence Erlbaum Associates, 1991, p. 89-136.

KINSEY, A.A. Atas: Congresso de Milão [de] 1880. Rio de Janeiro: Ines, 2011.

LABOV, William. Alguns passos iniciais na análise da narrativa. Trad. Waldemar Ferreira Netto. In: The Journal of Narrative and Life History. Vol. 7, n. 1-4.

LACERDA, Cristina Broglia de Feitosa; MANTELATTO, Sueli Aparecida Caporali. As diferentes concepções de linguagem na prática fonoaudiológica junto a sujeitos surdos. In: LACERDA, Cristina Broglia de Feitosa; NAKAMURA, Helenice; LIMA, Maria Cecília. Fonoaudiologia: surdez e abordagem bilíngüe. São Paulo: Plexus; 2000. p. 23-43.

LEVY, Cilmara Cristina Alves da Costa; BARBOSA, Felipe Venâncio. Surdez: Condutas na avaliação e planejamento terapêutico. In: LOPES-FILHO, O. Tratado de Fonoaudiologia. TecMedd, São Paulo, p. 377-389, 2005.

LODI, Ana Claudia Balieiro; HARRISON, K. M. P.; CAMPOS, S. R. L; TESKE, O. (Org.). Letramento e minorias. Porto Alegre: Mediação, 2002. 168p.

MORGAN, Gary; WOLL, Bencie. The development of reference switching encoded through body classifiers in British Sign Language. In: EMMOREY, K (Ed.) Perspectives on classifier constructions in sign languages. Mahwah, NJ: Lawrence Erlbaum Associates, 2003, p. 297-310.

MORGAN, Gary. The encoding of simultaneity in children's BSL narratives. Journal of Sign Language and Linguistics, v. 5, n. 2, p. 127-161, 2002.

OLIVEIRA, Adriana Stella Cardoso Lessa. Libras escrita: o desafio de representar uma língua tridimensional por um sistema de escrita linear. ReVEL, v. 10, n. 19, 2012. p. 150-184.

PACHECO, José Augusto. Escritos curriculares. São Paulo: Cortez, 2005. 176 p.

PETERSON, C.; MCCABE, A. Linking children's connective use and narrative microstructure. In: MCCABE, A.; PETERSON, C. (Eds.), Developing narrative structure. Hillsdale, NJ: Erlbaum, 1990. p. 29-53.

PICKERSGILL, Miranda. Bilingualism, current policy and practice. In: GREGORY, Susan et al. Issues in deaf education. Abingdon: David Fulton Publishers, 1998. p. 88-97.

QUADROS, Ronice Muller; KARNOPP, Lodenir Becker. Língua de Sinais Brasileira - Estudos Lingüísticos. ArtMed. Porto Alegre. 2004. 221p.

QUADROS, Ronice Muller. Educação de surdos: a aquisição da linguagem. Porto Alegre: Artes Médicas, 1997. $128 p$.

RATHMANN, Christian; MANN, Wolfgang; MORGAN, Gary. Narrative structure and narrative development in deaf children. Deafness \& Education International, v. 9, p. 187 - 196, 2007.

RODRIGUES, José Raimundo; VIEIRA-MACHADO, Lucyenne Matos da Costa. Primeiro Congresso Nacional para o Melhoramento das Condições dos Surdos-mudos - Lyon - 1879. Revista História da Educação (Online), 2019, v. 23. Available at <https://seer.ufrgs. br/asphe/article/view/93873> access on 01 June 2020.

RODRIGUES, José Raimundo. As Seções de surdos e de ouvintes no Congresso de Paris (1900): Problematizações Sobre o Pastorado e a Biopolítica na Educação de Surdos. Dissertação de Mestrado. Faculdade de Educação: Universidade Federal do Espírito Santo, 2018. 202p. 
SCLIAR-CABRAL, Leonor. Políticas Públicas de Alfabetização. I/ha Desterro [online]. 2019, v.72, n.3 [cited 202005-06], p. 271-290.

SECRETARIA MUNICIPAL DE EDUCAÇÃO. Currículo da Cidade: Educação Especial, Língua Brasileira de Sinais. SME; COPED, São Paulo, 2019a. 168p.

SECRETARIA MUNICIPAL DE EDUCAÇÃO. Currículo da Cidade: Educação Especial, Língua Portuguesa para Surdos. SME; COPED, São Paulo, 2019b. 184p.

SOUZA, Linete Oliveira de; BERNARDINO, Andreza Dalla. A Contação de histórias como estratégia pedagógica na Educação Infantil e Ensino Fundamental. Educere et Educare Revista de Educação, v. 6, n. 12, jul/dez, 2011, p. 235-249.

STUMPF, Mariane Rossi. Transcrições de língua de sinais brasileira em sign writing. In: LODI, A.C.B.; HARRISON, K. M. P.; CAMPOS, S. R. L.; TESKE, O. (Org.). Letramento e minorias. Porto Alegre: Mediação, 2002. p. 67-70.

Recebido em: 15/01/2020

Aceito em: 28/03/2020 